\title{
RESENHA \\ THE THEORY OF THE GROWTH OF THE FIRM
}

Penrose, E. The theory of the growth of the firm. White Plains, NY: M.E. Sharpe, 1959. 272p

Doutor em Engenharia de Produção pela Universidade Federal de Santa Catarina - UFSC. Professor no Departamento de Ciências da Administração da Universidade Federal de Santa Catarina - UFSC. Brasil. E-mail: andre.leite@ ufsc.br

Nei Antonio Nunes

Doutor em Sociologia Política pela Universidade Federal de Santa Catarina - UFSC. Professor da Universidade do Sul de Santa Catarina - UFSC. Brasil. E-mail: neinunes@bol.com.br

A obra de Edith Penrose tem sido constantemente citada nos trabalhos acadêmicos sobre estratégia como sendo precursora da escola que conhecemos como Visão Baseada em Recursos (VBR). Para melhor compreender as ideias contidas em sua obra principal convém mencionar a trajetória acadêmica e profissional da autora, bem como a conjuntura externa que a estimulou a escrever este livro.

Até a metade do século XX, a teoria econômica tradicional tratava a firma como sendo uma black box, ou seja, uma caixa preta na qual se injetava determinada combinação de insumos e ao final de um processo produtivo desconhecido produtos eram disponibilizados no mercado. Explicando melhor, não importava o que acontecia dentro da firma, mas sim as funções de produção, a produtividade e a produção total disponibilizada no mercado. A teoria microeconômica neoclássica era considerada uma ciência amadurecida e focava essencialmente na ideia dos mercados perfeitamente competitivos, ótimo de Pareto e alocação eficiente de recursos utilizando ferramentas matemáticas sofisticadas. Porém, de acordo com seus pressupostos teóricos é difícil explicar porque algumas firmas são maiores e têm desempenho, quer medido em forma de lucro, crescimento, ou outras maneiras, melhor que outras.

Deve-se destacar que Marshall em seus livros Principles of Economics e depois em Industry and trade já fazia tentativas de abordar teoricamente a firma por dentro, destacando questões como crescimento, comportamento, aspectos gerenciais e estrutura organizacional da firma. Este autor foi o ponto de partida de Penrose no início de sua pesquisa.

Assim, desde o fim do século XIX, com a observância do surgimento de grandes firmas, com expressivo poder de mercado e novas formas de organização começam a surgir livros fundamentais que criticaram o modelo de concorrência perfeita.com destaque para as obras de Piero Sraffa (1926), The laws 
of return under competitive conditions, e de Joan Robinson (1933), The economics of imperfect competition. Ambos, especialmente a última, dando destaque às estruturas de mercado intermediárias entre monopólio e concorrência perfeita, que permitem o surgimento das grandes corporações, colocando ênfase nas formas de competição, não se utilizava o termo estratégia da forma como utiliza-se atualmente, em especial, economias de escala, que permitiam redução de custos e diferenciação de produtos.

Paralelamente a isto, Edith Tilton (nascida em 1914) graduava-se em 1936 na Universidade de Berkeley, California. No mesmo ano, casou-se com David Denhardt, com quem teve um filho, tornando-se viúva dois anos depois. Então, mudou-se para Baltimore, onde em 1950, já casada com Ernest Penrose, obteve seu doutorado em economia pela John Hopkins University. Durante este período, Penrose participou de um projeto de pesquisa sobre $\mathrm{o}$ crescimento das firmas.

Após seu doutoramento, retornou à Universidade de Berkeley como docente. Porém, poucos anos após, Edith e seu marido foram acusados de serem espiões soviéticos pelo macartismo e, desiludidos, decidiram viver fora dos EUA. Primeiramente, seu destino foi a Austrália e depois Bagdá, onde teve a oportunidade de estudar o comportamento das grandes firmas de petróleo . Estas experiências foram fundamentais para confirmar as observações da autora acerca do processo de crescimento das firmas. Após a estada em Bagdá, estabeleceram-se em Londres, onde permaneceu até o fim da vida, em 1996.

Embora esteja claro que a obra-prima de Penrose, The theory of the growth of the firm, teve influência decisiva sobre, no campo da Estratégia, o surgimento da Visão Baseada em Recursos (VBR), convém notar que a questão de pesquisa que a autora quis responder era se há algo na natureza da firma que levava ao crescimento da firma ao mesmo tempo em que impunha limites ao crescimento. E por que teve tanta influência sobre o pensamento estratégico? Porque para responder tal pergunta era necessária uma definição da firma por dentro, nos moldes dos pioneiros da economia industrial, como Alfred Marshall, bem como de outras disciplinas que viam a firma como uma organização.

Em sua pesquisa, Penrose concluiu que a teoria da firma existente até o momento era insuficiente para explicar porquê e como as firmas crescem. $\mathrm{Na}$ introdução do livro, escreve a autora que: "há importantes restrições à velocidade com a qual as firmas crescem. Recursos humanos necessários à mudança estão ligados à firma individual e, portanto, são escassos. O crescimento requer a contratação de mais destes recursos e novos contratados não podem estar disponíveis da noite para o dia. O processo de crescimento da firma é, portanto, dinamicamente restringido". Ou seja, as restrições ao crescimento surgem do próprio ambiente interno, donde se conclui que os recursos produtivos apresentam-se simultaneamente como oportunidade e também como elementos que restringem o crescimento.

Se para Coase, em seu artigo de 1937, numa primeira tentativa heterodoxa de definição da firma, esta pode ser definida como um conjunto de contratos, para Penrose (1959), "uma firma não é um objeto observável de maneira fisicamente separada de outros objetos, e é difícil de se definir a não ser como referência ao que faz ou ao que é feito em seu interior. Consequentemente, cada analista é livre para escolher quaisquer características da firma nas quais esteja interessado, definir a firma em termos destas características e proceder de forma a chamar sua construção de firma" (Penrose, 1959, p.10).

Penrose, de forma ampla, arquiteta uma concepção de firma que analisa objetivos, hierarquia, crescimento, fusões e aquisições, e diversificação. Entretanto, embora discuta a grande firma de sua época, a autora não envereda pela ideia da separação entre propriedade e controle. Ela, então, define a firma como sendo uma "coleção de recursos produtivos cuja disposição entre diferentes usos e ao longo do tempo é determinada por razões administrativas" (Penrose, 1959, p.24). A coleção de recursos produtivos visa ao objetivo único do crescimento, o que equivale ao objetivo de maximização de lucros no longo prazo.

Convém também (re)lembrar que o intuito de Penrose era entender as causas do crescimento da firma e seus limites, i.e., limites internos e o ambiente externo. Para ela, o crescimento é fundamentalmente causado pela dotação de recursos de uma determinada firma. Com base na análise dos recursos, e de suas propriedades, é que se pode analisar a influência do ambiente externo sobre a firma.

Penrose também propõe que, para fins analíticos, o objetivo da firma seja o crescimento, contrariando a lógica heterodoxa maximizadora de lucros. O objetivo crescimento abarca outros menos amplos, como aumento das vendas ou do market-share, por exemplo. A percepção da firma como uma coleção de recursos apresenta uma expressiva coragem da autora, dado que rompe com a tradição microeconômica neoclássica, já que para esta escola os recursos são apenas insumos de uma função de produção usada pelas firmas.

O lucro, em sua concepção, deveria ser reinvestido para o crescimento futuro da empresa. Em sua obra também está a tentativa de compreensão da heterogeneidade entre as firmas, e a consequente diferença de desempenho entre as empresas. De acordo com a autora, as firmas deveriam ser analisadas e compreendidas como um quadro administrativo que coordena atividades de vários indivíduos.

Outro ponto importante refere-se à heterogeneidade de recursos, que é de suma importância para se entender sua influência sobre a Estratégia como campo de estudo. Penrose observara 
que mesmo firmas atuando em um mesmo setor da economia tendem a ter desempenho diferente graças, em especial, ao fato de possuírem, e gerirem, recursos de formas distintas.

Ao definir a firma como uma coleção de recursos, o trabalho de Penrose tem sido considerado o precursor da VBR. A autora não restringiu a definição de recursos produtivos, ou seja, adotou uma definição bastante ampla. Para ela, o essencial era que os principais recursos tivessem oferta inelástica, ou seja, essenciais para o bom desempenho da firma. Mesmo utilizando uma classificação ampla de recursos, reconheceu a autora que pode haver fontes de heterogeneidade entre as firmas. Daí, a principal, na obra da autora, explicação sobre a diferença de desempenho entre as firmas.

Em relação ao processo competitivo, no capítulo sobre Diversificação, a autora propõe que o crescimento por diversificação pode ser, se bem gerenciado, eficiente, o que já mostrava a preocupação da autora com os conglomerados ou holdings. Oliver Williamson depois utilizaria o livro de Penrose como base para seus estudos sobre a estrutura administrativa e operações gerenciais, bem como para sua análise da forma Multi-divisional, ou forma-M, na qual as decisões estratégicas concentram-se no topo das grandes empresas, seguidos por um corpo altamente qualificado de funcionários que examinam as opções estratégicas e supervisionam as operações de subsidiárias, ou quasi firmas.

Foi Wenerfelt, em seu texto A Resource-Based view of the firm, de 1984, que resgatou a discussão iniciada por Penrose, formalizando a VBR como uma teoria que afirma que a vantagem competitiva tem como principal fonte os recursos de que a firma dispõe. Ou seja, para Wenerfelt (1984), a partir da heterogeneidade dos recursos proposta por Penrose, as forças competitivas de uma firma estão centradas em suas competências distintas, caracterizadas pela posse de recursos distintos.

Está na obra de Penrose, por fim, o primeiro ensaio consistente e rigoroso visando a mostrar a importância da análise estratégica da heterogeneidade de recursos como fonte de obtenção dos chamados monopólios temporários, ou vantagem competitiva. Assim, a VBR é eminentemente uma escola teórica derivada do pensamento de Penrose, evoluindo constantemente a partir da contribuição teórica e empírica de diversos autores, referendando com excelência a investigação da autora. A partir da sua obra, a natureza da firma tornou-se foco central de inúmeras investigações científicas, contribuindo para melhor compreensão das fontes de vantagem competitiva, da gestão empresarial e do desempenho das empresas. 